This item was submitted to Loughborough's Research Repository by the author.

Items in Figshare are protected by copyright, with all rights reserved, unless otherwise indicated.

\title{
Work factors related to psychological and health-related distress among employees with chronic illnesses
}

PLEASE CITE THE PUBLISHED VERSION

PUBLISHER

(C) Springer

VERSION

AM (Accepted Manuscript)

LICENCE

CC BY-NC-ND 4.0

\section{REPOSITORY RECORD}

Munir, Fehmidah, Joanna Yarker, Cheryl Haslam, Helen Long, Stavroula Leka, Amanda Griffiths, and Sarah Cox. 2019. "Work Factors Related to Psychological and Health-related Distress Among Employees with Chronic Illnesses". figshare. https://hdl.handle.net/2134/4856. 
This item was submitted to Loughborough's Institutional Repository (https://dspace.lboro.ac.uk/) by the author and is made available under the following Creative Commons Licence conditions.

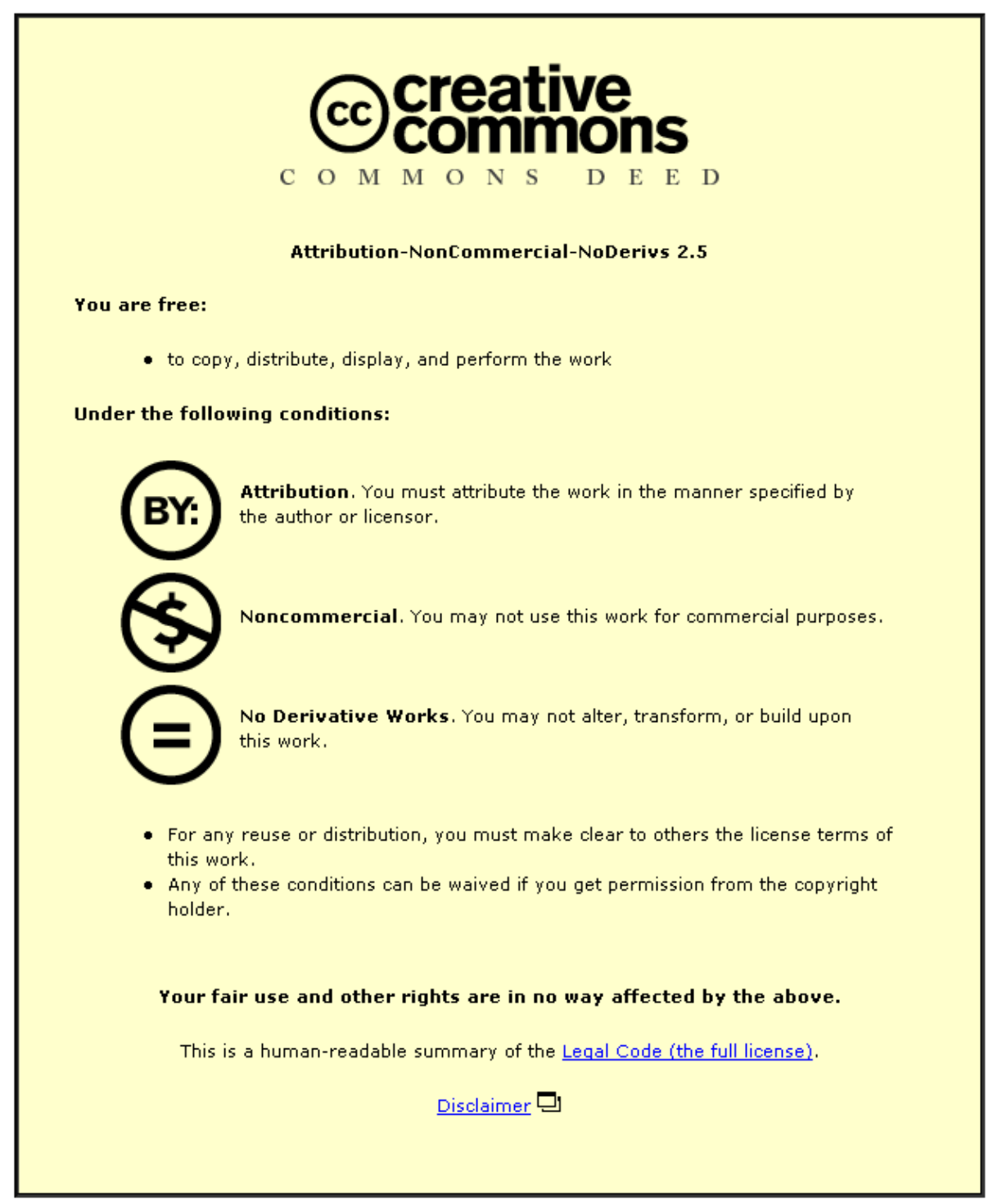

For the full text of this licence, please go to: http://creativecommons.org/licenses/by-nc-nd/2.5/ 
WORK FACTORS RELATED TO PSYCHOLOGICAL AND HEALTHRELATED DISTRESS AMONG EMPLOYEES WITH CHRONIC ILLNESSES

${ }^{1}$ Dr Fehmidah Munir, ${ }^{2}$ Dr Joanna Yarker, ${ }^{1}$ Professor Cheryl Haslam, ${ }^{3}$ Ms Helen Long, ${ }^{4}$ Dr Stavroula Leka, ${ }^{4}$ Professor Amanda Griffiths, ${ }^{4}$ Dr Sara Cox.

Published in: Journal of Occupational Rehabilitation, 2007, 17; 259-277.

${ }^{1}$ Department of Human Sciences, Brockington Building, Loughborough University, Loughborough, Leicestershire LE11 3TU, UK.

${ }^{2}$ Goldsmiths College, University of London, New Cross, London SE14 7NW, UK.

${ }^{3}$ Organisational Development Team, Department of Work and Pensions, B3 Porterbrook House, 7 Pear Street, Sheffield S11 8JF, UK.

${ }^{4}$ Institute of Work, Health \& Organisations, University of Nottingham, University Boulevard, Nottingham NG7 2RQ, UK.

Correspondence and reprints to: Dr Fehmidah Munir

Department of Human Sciences, Brockington Building, Loughborough University, Loughborough, Leicestershire LE11 3TU, UK.

Tel: +44 (0)1509 228228; Fax: +44 (0)1509 223940

email: F.Munir@lboro.ac.uk

Total words: 7963

Running title: Psychological distress in employees

\section{ACKNOWLEDGEMENTS}


This work was supported by a grant from the European Social Fund awarded to the first author during her employment at the Institute of Work, Health and Organisations (IWHO), University of Nottingham UK, where the work was carried out. 


\begin{abstract}
Objective: This study examined specific psychosocial factors associated with psychological and health-related distress amongst employees reporting different chronic illnesses.

Methods: The sample consisted of 1029 employees managing either musculoskeletal pain $(\mathrm{n}=324)$, arthritis and rheumatism $(\mathrm{n}=192)$, asthma $(\mathrm{n}=174)$, depression and anxiety $(\mathrm{n}=$ $152)$, heart disease $(\mathrm{n}=96)$ or diabetes $(\mathrm{n}=91)$. Information on psychological distress, work limitations, illness management, disclosure, absence, presenteeism, support and demographic factors were obtained through self-administered questionnaires. Results: Both low psychological well-being and high health-related distress were associated with an increase in work limitations $(\beta=0.20, S E=.03$; and $\beta=0.19, S E=.01$, respectively), poorer management of illness symptoms at work $(\beta=-0.17, S E=.12$; and $\beta=-0.13, S E=.02)$, high presentieesm $(\beta=$ $0.19, S E=.25$; and $\beta=0.14, S E=.05)$ and low workplace support $(\beta=-0.05, S E=.22$; and $\beta=-$ $0.12, S E=.05)$. Health-related distress was additionally associated with disclosure of illness at work $(\beta=0.18, S E=.08)$ and long-term sickness absence $(\beta=0.10, S E=.06)$. Conclusions: To enable individuals to effectively manage both their illness and their work without serious repercussions, it is important for both healthcare professionals and employers alike, to improve the well-being of workers with chronic illness by supporting and facilitating their efforts to over-come health-related limitations at work.
\end{abstract}




\section{Introduction}

Psychological distress in patients with chronic illness such as heart disease, cancer, musculoskeletal pain and diabetes are well documented (1-5). The experience of distress is known to substantially affect an individual's disease prognosis and overall quality of life (6). A number of biopsychosocial factors have been associated with distress in chronic illness patients, particularly in relation to depression as a chronic illness and as a symptom of low psychological well-being in other chronic illnesses $(7,8)$. Factors associated with distress include clinical status such as disease severity, presence of pain and fatigue; low functional status (i.e. ability to carry out daily activities); and demographic factors such as younger age, lower income and lower educational level $(4,9)$. Psychological distress has also been associated with patients' perception of their own health status and functioning $(10,11)$, poor self-management of illness (e.g. inconsistent medication use, poor monitoring of symptoms and adherence to diet), poor coping mechanisms and social factors such as low social support (11-13).

Most of this research has examined the psychosocial factors contributing to distress in chronic illness patients outside of a contextual environment. One significant contextual environment with the potential to influence distress is the workplace. It is estimated that between $15-20 \%$ of the working-age population are likely to be managing a chronic illness of which approximately $5 \%$ is attributed to work-related causes $(14,15)$. The psychological status of employees with work-related illnesses is well-established. Such studies typically report that exposure to psychosocial work environments such as high work demands/low control and low workplace support are associated with both general psychological distress and job-related psychological distress (16-18). In addition, general life events, poor work-life balance, high levels of absence and more recently high levels of presenteeism (attending work despite feeling unwell) have also been associated with both general psychological distress and job-related psychological distress (e.g., 19, 20). Despite the rising prevalence of chronic 
illness among the working population, such factors have seldom been examined within the work environment. This represents a significant gap in research.

Akabas and Gates (21) suggest that psychological distress in employees managing chronic illness is complex and affected by multiple psychosocial factors. Such employees not only need to manage the experience of work and exposure to psychosocial work environments, they are also required to manage their illness within this context. To this end, such employees may experience different kinds of psychological distress. Two of the most well-documented types are general psychological distress and health related distress. General psychological distress refers to feelings of strain, depression, inability to cope, lack of confidence, inability to carry out daily activities and other psychological problems (22). Health related distress on the other hand, is associated with health status and its related illness demands, adjustments and psychosocial situations to which the individual must adapt (23).

Feelings of general psychological distress can be produced by a wide range of life events including work-related factors $(17,24)$. Within a workplace setting, general psychological distress is thought to encompass the same general construct of job dissatisfaction $(19,25)$. Although both are affective states, psychological distress differs in being characterised not only by feelings of unhappiness but also by feelings of depression and anxiety, the primary dimensions of negative affect and mood (25). It is therefore considered that general psychological distress for employees managing a chronic illness is more likely to be associated with work-related factors such as workplace support, absence, presenteeism and work limitations. In contrast, while health-related distress may also be associated with work limitations and presenteeism, it is more likely to be associated with health specific factors such as disclosure of illness and self-management of illness at work by chronically ill employees. 
A review of the literature suggests that whilst different chronic illnesses have been associated to varying degrees of work limitations (26), there has been little examination of the relationship between work limitations and psychological distress. Self-management of illness has previously been linked to psychological distress (13) but few studies have examined this relationship within a work setting $(26,27)$. The relationship between presenteeism and distress has also not been adequately examined among different chronic illness groups, although studies are beginning to emerge which suggest high presenteeism is common among those with low income and high job demands (28) and common among those with hypertension, heart disease, depression and arthritis (29). While the economic burden of presenteeism is documented for such illness groups, the relationship between presenteeism and psychological and health-related distress has not been directly examined. More recently, disclosure of illness in the workplace has been examined across a range of chronic illnesses. These suggest disclosure of illness can be perceived as a behaviour strategy to access workplace support and work adjustments (27). However, it can also potentially lead to workplace discrimination (30). Self-disclosure can therefore either lead to a reduction in psychological distress or an exacerbation $(27,31)$, although this has not yet been examined using measures of psychological distress. Understanding the relationship between these psychosocial factors and distress among employees managing chronic illness is important, especially when unrecognised distress can lead to the development of psychological morbidity. There is a growing body of evidence indicating that well-designed and wellimplemented employer and healthcare interventions can reduce the incidence of psychological and health-related distress and subsequently improve employment outcomes among such illness groups $(2,19,32,33)$.

By utilising two distinct measures of distress, this study aimed to examine the psychosocial factors associated with both psychological and health-related distress, particularly those factors that have received limited attention in the context of the work environment among employees with chronic illness. These include disclosure of illness, self-management of 
illness and presenteeism. The study also aimed to examine this relationship among six different chronic illness groups: musculoskeletal pain, arthritis and rheumatism, depression and anxiety, asthma, heart disease and diabetes. In line with previous research (19), it is expected that those with depression and anxiety would show higher levels of distress than other illness groups. We hypothesized that when controlling for demographic, illness severity and chronic illness group differences, the psychosocial factors outlined above would additionally contribute to distress experienced in the workplace.

\section{Method}

\section{$\underline{\text { Participants }}$}

The sample is based on cross-sectional questionnaire data and participants were workers from four organisations across three sectors: local government, transport and manufacturing (two companies). To ensure anonymity employees, regardless of their health status, were randomly sent a questionnaire through the occupational health departments. The strategy for sending questionnaires varied according to organisational size (ranging from 5,000 to 21,000 employees). We approached all employees in the two manufacturing companies (both employing 5,000 employees), and randomly selected 1:3 employees in the local government (employing 21,000 employees) and 1:2 employees in the transport organisation (employing 12,00 employees). Workers were invited to volunteer for the study by completing the questionnaire. Completed questionnaires were returned directly and anonymously to the research team. To monitor overall response rates, the questionnaire asked all employees, independent of their health status for demographic and job-related details (age, gender, tenure and occupation). Employees managing a chronic illness were asked additional questions about their health and work. A $28 \%$ response rate was achieved for completed returned questionnaires (response rates ranged from $26 \%$ to $30 \%$ ). This is a below average response rate for mailed surveys in organisational research of this type $(34,35)$. Discussions with the organisational stakeholders indicate that response rates for questionnaires outside of annual employee surveys are in the region of $27-31 \%$ due to survey fatigue (36). The low response 
rate in this study be also be expected given the study's focus on chronic illness, which may have seemed irrelevant to many workers. Out of the completed questionnaires, 28\% (1474 participants) reported at least one chronic illness. In comparison, the European Foundation for the Improvement of Living and Working Conditions (37) estimated 15\% of the workingage population in Europe to be managing a chronic illness or disability. The remaining sample did not report a chronic illness and were therefore excluded from the present analysis.

Participants were asked in the questionnaire to self-report on any medically diagnosed chronic illness they currently experienced, and to indicate which primary condition (if more than one was listed) most affected their work. This measure was developed to be consistent with other self-report measures of chronic illness $(27,38,39)$. A total of 17 different groups of chronic illnesses were identified from the sample using the International Classification of Diseases (40): musculoskeletal pain $(n=324$, those reporting pain anywhere along the musculoskeletal system: back, shoulders, neck, arms, elbows, wrist and lower limbs), arthritis and rheumatism $(\mathrm{n}=192)$, asthma $(\mathrm{n}=174)$, depression and anxiety $(\mathrm{n}=152$, those reporting either depression, anxiety or a combination of both), irritable bowel syndrome ( $\mathrm{n}=115)$, heart disease ( $n=96$, those reporting myocardial infarction, angina, heart failure, stroke and hypertension [ $39 \%$ of heart disease sample]), diabetes $(n=91,74 \%$ reporting diabetes II), migraine ( $\mathrm{n}=80$ ), thyroid disease $(\mathrm{n}=51,41 \%$ reporting hypothyroidism), inflammatory bowel disease ( $n=43,40 \%$ reporting crohn's disease), cancer ( $n=25,40 \%$ reporting breast cancer), reproductive and gynaecological problems $(n=17)$, multiple sclerosis $(n=17)$, eye problems $(\mathrm{n}=16)$, chronic fatigue syndrome $(\mathrm{n}=16), \mathrm{HIV}$ and hepatitis $(\mathrm{n}=16)$, epilepsy $(\mathrm{n}=14)$. An additional group, classified as 'Other', represented smaller numbers of other reported chronic illnesses $(n=35)$. For the purpose of this study, six of these groups were selected for analysis: musculoskeletal pain, arthritis and rheumatism, asthma, depression and anxiety, heart disease and diabetes; resulting in total of 1029 participants. These chronic illness groups were chosen for several reasons. First, these illnesses are the most prevalent reported at work in this sample and in national surveys (e.g. 15). Second, they are associated with high economic 
burden such as high sickness absenteeism, presenteeism and reduced work productivity (e.g. 28, 29). Third, they are reported to be associated with psychological distress (1-5).

\section{$\underline{\text { Measures }}$}

I. Illness management at work: Illness management (also referred to as self-management or self care) refers to the full range of activities that individuals with chronic illness carry out in order to promote their health, increase their physical, social or emotional resources, and prevent further health deterioration from their disease (41). For example, monitoring and responding to symptoms, managing acute episodes, taking medication and obtaining support from significant others $(27,41,42)$. As previously mentioned, much of the research into self-management of illness has focused on individuals using such strategies in settings outside the workplace. To measure whether participants were carrying out specific illness-related self management behaviours at work, a modified version of the illness symptoms Self-Management Behaviours Scale was used $(42,43)$. Based on the scale developed by Lorig et al (42) and Clark and Dodge (43), participants were asked to rate how closely they were following the advice of their doctor in carrying out various self-management activities specific to their chronic illness whilst at work. This was measured by eight items which asked participants to rate how closely they were following the advice in taking prescribed medication(1 item), managing illness symptoms as advised by their doctor (e.g. monitoring symptoms such as blood glucose levels, responding to symptoms such as asthma symptoms; 4 items), taking time off for treatment ( 1 item) and making minor changes to their work because of their illness ( 2 items). All responses were measured on a 10 point Likert scale (following advice not closely at all to very closely) and had an internal consistency of $\alpha=.73$. The mean of all items was calculated to yield a single score for managing chronic illness at work, where a higher score indicated more active management. 
II. Disclosure of illness: Disclosure of chronic illness was measured by four items that asked participants about the type of information they had disclosed at work with regard to their illness (the name of the illness and its symptoms, how the participant manages the illness at work, the affect of the illness on work performance and whether participants required time off work for treatment). For each item, participants were asked to indicate to what extent they had shared information about their illness with their line manager, co-workers or occupational health. Items were measured on a five point Likert scale (not at all to full disclosure), and had an internal consistency of $\alpha=$ .89. A mean score was calculated across all items to represent a single score of overall disclosure at work.

III. Work limitations: The Work Limitations Questionnaire was used to assess work performance (44). This measures the degree to which participants' symptoms of chronic illness interfered with specific aspects of daily job performance. The questionnaire has good content validity, item and scale reliability (43). The questionnaire asks participants to rate on a five point Likert scale, their level of difficulty (or ability) to perform 25 specific job demands. Responses to the 25 items are combined into four work limitation scales: time management (e.g. work the required number of hours, five items, $\alpha=.88$ ), physical demands (e.g. able to walk or move around different work locations, six items, $\alpha=.90$ ); mental interpersonal (e.g. think clearly when working, nine items, $\alpha=.92$ ) and output demands (e.g. finish work on time, five items, $\alpha=.94)$. These capture the multi-dimensionality of job roles. A total scale score was calculated to indicate overall work limitation, where a higher score indicated more work limitation (or work productivity loss) (43).

IV. Sickness absence: Absence related to chronic illness was measured by asking participants to estimate the number of times they had been absent from work over the 
last 12 months because of their illness. Data were collected on spells of 1-day absence, spells of 2-4 days absence and spells of 5-days or more absence (as an indicator of long-term certified sickness absence). This captures both absence frequency and absence duration $(45,46)$, and is consistent with other self-report sickness absence measures $(47,48)$. Such measures, when compared with organisational records of absence data have a convergent validity of .62 and above $(47,49)$.

V. Presenteeism: Consistent with the absence measure, Presenteeism related to chronic illness was measured by asking participants to estimate the number of times they had attended work despite feeling unwell because of their illness over the last 12 months. Data were collected on spells of 1-day presenteeism, spells of 2-4 days presenteeism and spells of 5-days or more presenteeism.

VI. Instrumental workplace support: Support consisted of two forms of workplace support: practical support (i.e. giving information and practical help and advice) and emotional support (i.e. demonstration of sympathy and understanding). These were both measured with three items each, representing support received from colleagues, line manager and occupational health in the management of chronic illness. Items were measured on a five-point Likert scale (no support to a great deal of support) and had an internal consistency of $\alpha=.83$ and $\alpha=.81$ in this sample. A total mean scale score was calculated to indicate overall instrumental workplace support (bivariate correlation was $r=.72$ for the two scales) with a higher score indicating more support.

VII. Illness severity: Severity of illness symptoms (one item) was measured on a seven-point Likert scale (very mild to very severe). The total number of chronic illnesses managed per participant was also measured. 
VIII. Psychological distress: Psychological distress was assessed with the 24-item General Wellbeing Questionnaire (GWBQ) (22). This symptom-based instrument assesses two aspects of poor general well-being: exhaustion (or 'worn out') (12 items) and anxiety and tension (or 'uptight') (12 items). The exhaustion scale measures three aspects of poor well-being: fatigue, mental confusion and emotional irritability $(\alpha=.84)$. The anxiety and tension scale measures symptoms of fear, worry, tension and physical signs of anxiety $(\alpha=.83)$. The GWBQ has good concurrent validity with regard to other measures of general health, overt ill-health and fatigue in different group settings; and is a consistent and reliable instrument when used in both health-related and workrelated research $(22,24)$. All items were measured on a five-point Likert scale and participants indicated the frequency of their symptoms with reference to a six month time window. Scores on each scale were calculated with a range of 0 to 48 from the answers to the 12 items on each scale. A total mean scale score was calculated to indicate overall general well-being (bivariate correlation was $r=.80$ for the two scales) with a higher score $(\geq 25)$ indicating psychological distress.

IX. Health-related distress: Health-related stress was measured by the health distress scale in participants reporting a chronic illness only (4 items) (50). The scale, taken from the MOS survey of health status (50), measures symptoms of depression, anxiety and positive affect ( $\alpha=.89)$. The psychometric properties of the scale, including internal consistency, content and construct validity have been proven to be good (50). All items were measured on a five-point Likert scale and participants indicated the frequency of their symptoms with reference to the past four weeks. A mean score was calculated for the health distress scale, with a higher score indicating greater distress about health.

$X$. Demographics: Data were collected on age (in years), gender $(0=$ male, $1=$ female $)$, tenure (length of employment in years), occupational group (higher managerial and 
professional, lower managerial and professional, intermediate, lower supervisory and technical, semi routine and routine occupations; based on National Statistics Socioeconomic Classification of eight-digit occupational titles for England and Wales) and education (none, GCSE or equivalent, $\mathrm{AS}$ and A level or equivalent, and degree).

\section{$\underline{\text { Analyses }}$}

All analyses were conducted using SPSS version 13.0. Preliminary analysis of the absence data revealed no significant differences between spells of 1 day and 2-4 days absence ( $>$.05), therefore figures for 1 day and 2-4 days absence were summed to give each participant's total number of non-certified absence frequency and duration. Hence, noncertified and certified absence indices were employed in the analyses. A similar pattern was found with the presenteeism data between spells of 1 day and 2-4 days presenteeism ( $p>.05)$, therefore two indices of presenteeism were employed in the analyses, spells of $<5$ days and spells of $\geq 5$ days absence. Since the absence data and the disclosure data had a skewed distribution, square -root transformations of these variables were used in the analyses. Mean general psychological well-being and health-related distress scores were compared between the different chronic illness groups using multivariate analysis of co-variance (MANCOVA) and Tukey's post hoc analyses. Univariate analyses (ANCOVA) was also carried out with illness management, work limitation, disclosure, support, absence and preseteeism variables. For all analyses, illness group was entered as the independent variable. Age, gender, socioeconomic status, organisation, education, severity of illness and the number of chronic illnesses managed were entered as covariates. Bonferroni correction test was applied where an alpha level of $\mathrm{p} \leq .003$ was accepted as statistically significant.

Multivariate hierarchical linear regression models were performed separately for the two outcome variables: general psychological well-being and health distress. The analyses were performed in three steps to examine the factors associated with psychological and health- 
related distress. Demographic covariates were first entered into the model (block 1). Next, illness groups, illness severity and the total number of chronic conditions managed were entered in block 2. Finally, all work-related factors (illness management, disclosure, work limitations, support, absence and presenteeism) were entered simultaneously into the model to examine the contribution made by the variables to psychological and health-related distress at work (block 3). The multicollinearity among all study variables was examined and found not to be at a level that would be problematic for the planned analyses (all VIF values well below 10 and tolerance statistics all well above 0.2). Each illness group was treated as a separate dummy predictor variable with each illness group contrasted against all other groups. Gender was also entered into the analyses using dummy coding $(0=$ male $)$.

\section{Results}

Table 1 shows the demographic details for participants reporting a particular chronic illness. This was compared with data obtained from each organisation's Human Resources department (non-responders). Participants with chronic illnesses did not significantly differ from their respective colleagues in terms of gender and socio economic status (all $p>.05)$.However, those reporting heart disease and arthritis and rheumatism were significantly older than non-responders $(p<.05)$. Within the sample, participants with depression and anxiety, asthma and musculoskeletal pain were generally younger than the other participants. Those with arthritis and rheumatism were significantly more likely to be female and those with heart disease or diabetes were significantly more likely to be male compared with the other groups. Those with musculoskeletal pain, depression and anxiety and arthritis and rheumatism reported their illness symptoms to be more severe compared to the other groups. The groups did not significantly differ on any other characteristic, although there was a trend for those with anxiety and depression, heart disease and diabetes to report slightly higher economic status (i.e. in lower managerial and professional groups) compared with the other groups. Those with depression and anxiety also generally reported higher level of education 
and those with arthritis and rheumatism reported lower education, compared with other groups although neither findings reached significance.

Multivariate analysis of co-variance with the two measures of psychological and healthrelated distress as the dependent variables revealed a significant effect of Group $F(5,898)=$ $37.38, p<.0001$. Univariate analyses of this main effect revealed significant differences in general psychological distress and health distress scores among the chronic illness groups [psychological distress: $F(5,898)=39.02, p<.0001$; and health-related distress score: $F(5$, $898)=9.82, p<.0001]$. As Table 2 shows, compared with other groups, participants with depression and anxiety reported higher scores on the general psychological distress and on the health distress measure. Participants with arthritis and rheumatism and musculoskeletal pain also reported higher scores on the health distress measure (post hoc Tukey, all $p<.001$ ).

Univariate analyses with the illness management, disclosure, work limitations, support, absence and presenteeism measures revealed a significant difference between the groups in illness management $[F(5,907)=19.71) p<.0001]$, work limitation $[F(5,907)=11.44$, $p<.0001]$, disclosure $[F(5,907)=4.94, p<.0001]$, and frequent short spells of presenteeism $[F(5,907)=3.90, p<.002]$. As Table 3 shows, post hoc Tukey analyses revealed those with depression and anxiety, arthritis and rheumatism and musculoskeletal pain reported lower illness management at work than the other illness groups. Those with depression and anxiety reported higher scores in work limitation compared with all other groups, followed by those with musculoskeletal pain and arthritis and rheumatism. Those with asthma reported lower disclosure rates than all other groups, except those with depression and anxiety. Finally, those with asthma generally reported less frequent short spells of presenteeism than those with arthritis and rheumatism and depression and anxiety. Those with depression and anxiety reported more frequent short spells of presenteeism than all other groups except those with arthritis and rheumatism. The groups did not differ on measures of support, absence and long spells of presenteeism. 


\section{Correlation analyses}

The intercorrelations among the predictor variables against the outcome variables of psychological and health-related distress is shown in Table 3. The correlation between the two measures of distress $(r=<0.47)$ does not pose problems with multicollinearity, indicating that both measures capture different aspects of distress. Except for gender and educational level, other demographic control variables did not significantly correlate with measures of psychological or health-related distress. Therefore, both gender (against the health-related distress measure only) and educational level were used as covariates in the subsequent analysis. Both illness severity and number of chronic illnesses managed correlated with psychological and health-related distress measures and were therefore also used as covariates in the regression analyses. Except for frequent spells of $<5$ days absence, all predictor variables were significantly associated with the two measures of psychological and healthrelated distress (disclosure was associated with only health-related distress). As both measures of distress varied by type of chronic illness, not tabled, all $p<.05$ ) each chronic illness group variable were entered as covariates with illness severity and number of chronic illnesses managed.

\section{Multiple hierarchical regression analyses}

The results of the multiple hierarchical regression analyses are presented in Table 4 . Analyses were run controlling for gender and educational level in block 1 and for illness severity, number of illness managed and each chronic illness group in block 2. For general psychological distress, the two demographic covariates explained 3\% of the variance. Block 2 accounted for an additional $24 \%$ with those managing depression and anxiety making the strongest contribution $(\beta=0.30, S E=.59 ; p<.0001)$. Finally, after controlling for both 
demographics, illness severity and each chronic illness group, the final regression model (block 3 ) accounted for an additional $15 \%$ of the variance. Work limitations $(\beta=0.20$, $S E=.03 ; p<.0001)$, frequent spells of presenteeism $(<5$ days and $\geq 5$ days $)(\beta=0.19, S E=.25$, $p<.0001$; and $\beta=0.17, S E=.43, p<.0001$; respectively), poor management of illness at work $(\beta=-0.17, S E=.12, p<.0001)$ and workplace support $(\beta=-0.05, S E=.22 ; p<.05)$ all contributed to general psychological distress.

For health-related distress, educational level (block 1) explained 1\% of the variance. Block 2 accounted for $19 \%$ of the variance with illness severity making the largest contribution. After controlling for educational level, illness severity and each chronic illness group, the final regression model (block 3) accounted for an additional 15\% of the variance. Again, work limitations $(\beta=0.19, S E=.01, p<.0001)$, disclosure of illness $(\beta=0.18, S E=.08, p<.0001)$, frequent spells of presenteeism ( $<5$ days and $\geq 5$ days) $(\beta=0.14, S E=.05, p<.0001$; and $\beta=$ $0.10, S E=.08, p<.01$, respectively), poor management of illness $(\beta=-0.13, S E=.02, p<.0001)$, workplace support $(\beta=-0.12, S E=.05, p<.0001)$, and frequent spells of $\geq 5$ days absence $(\beta=$ $0.10, S E=.06, p<.01)$ all contributed to health-related distress.

\section{Discussion}

This study examined the psychosocial factors associated with distress among employees managing a chronic illness, using two distinct measures of psychological distress: general psychological well-being and health-related distress. In line with previous research, (e.g. 19) those managing depression and anxiety showed higher levels of both psychological and health-related distress at work. In addition, those with musculoskeletal pain and arthritis and rheumatism also showed higher levels of health-related distress. Both depression and anxiety and musculoskeletal pain have been associated with one of the most prevalent causes of work-related ill-health and high sickness absence $(2,15)$. Psychological distress has also been reported in those managing arthritis at work $(51,52)$. As previously mentioned, the 
purpose of this study was to examine the psychosocial factors associated with both psychological and health-related distress, particularly those factors that have not been previously considered in the context of the work environment among employees with chronic illness. Our results suggest that once the type of illness and illness severity are accounted for, work limitations were the strongest predictors for both measures of distress followed by presenteeism and poor illness management with general psychological distress; and disclosure, presenteeism and poor illness management with health-related distress.

Work limitations were strongly associated with both general psychological and health-related distress. This indicates that both the impact of daily job performance on the illness and the extent to which the illness itself interferes with getting the job done affects both psychological well-being and health-related distress. It is clear that both health-care and employer-based interventions are required which identify and address both patterns of work limitations and psychological health outcomes in those managing a chronic illness at work. This is especially the case for those considered 'at risk' of high levels of work limitations and associated psychological and health-related distress, for example, those with depression and anxiety. Consistent with previous research, those with depression and anxiety, musculoskeletal pain and arthritis and rheumatism reported significant work limitations compared with other illness groups (e.g. 53). Our results are also consistent with Akabas and Gates' (21) findings in that increased self-reported work limitations are associated with the experience of psychological distress in employees with chronic illness. Akabas and Gates' examined psychological and health-related distress in those with severe illnesses such as cancer, multiple sclerosis and those with post transplant problems. Our findings add to this literature.

In the present study, we found an association between both frequent short spells and long spells of presenteeism and both measures of general psychological and health-related distress. This suggests that many employees managing a chronic illness are not able to take time off to manage their illness when required (e.g. when symptoms are exacerbated). This could either 
indicate the difficulties in finding a replacement or a stand-in for absenteeism (28). The association between presenteeism and distress could also indicate strict attendance polices where employees feel unable to take time off work because of their chronic illness. This is perhaps most likely the case in this sample, as data collected from each organisation showed attendance management policies that operated on a 'trigger points' system, whereby employees were penalised for high spells of short-term absence. The distress associated with this type of system for those employees managing a chronic illness is reflected in the present results. Although absence was not associated with general psychological well-being, longterm absence (spells of $\geq 5$ days) was associated with health-related distress. Together, these results suggest that employees continue to attend work despite feeling unwell, and that this behaviour may intensify their illness symptoms leading to increased health-related distress and long-term absence.

The association between presenteeism and distress could further indicate poor illnessmanagement skills in those with chronic illness. The present study found illness management negatively associated with distress indicating that poor self-management of illness at work is associated with increasing levels of both general psychological distress and health-related distress. Poor management of illness may indicate a poor coping mechanism such as behavioural disengagement, or poor adaptation to chronic illness $(1,27)$. In a previous study, Munir et al $(27,30)$ found that chronically ill employees who displayed effective selfmanaging illness behaviours at work were also more likely to be proactive in other aspects of managing illness at work such as disclosing their illness to access workplace support. Livneh and colleagues (13) affirm that patients with a chronic illness who demonstrate lower overall psychological distress, report greater reliance on problem-focused strategies, more frequent perceptions of control over their illness and lower perceived levels of functional limitations. Effective coping mechanisms are considered to moderate the experience of distress (12). Although we have not looked at coping mechanisms in this study, our results indicate that poor self-management of illness at work and lower perceived work limitations may suggest / 
reflect the adoption of ineffective coping strategies. This may prompt such employees to, for example, disclose their illness in order to access appropriate support to manage their illness and their work better. In the present study, high disclosure rate was associated with high levels of health distress. While the direction of causality cannot be affirmed from the present study, it is postulated that the higher the health-related distress experienced, the more likely chronically ill employees are to disclose their illness. Thus, disclosure itself could be perceived as a coping strategy (27) and as a means to accessing support. Although previous research suggests that disclosing personal information in the workplace can lead to increased harassment, discrimination and psychological distress (see 27), our results provide tentative support for our premise that employees are more likely to disclose if they are experiencing health-related distress. In this study, support was negatively associated with health-related distress. Further studies are warranted to delineate the relationship between disclosure and distress.

The importance of support in buffering or ameliorating the experience of psychological stress is well documented (12). In this present study, it is most likely that without appropriate support, employees are unable to carry out their work tasks efficiently or manage their illness effectively (30), thus leading to the experience of distress at work. Previous studies in chronically ill patients have focused on the effects of receiving support from either health care or families against the outcome of psychological health. The present study highlights the importance of considering the impact of receiving low levels of both practical and emotional support from the patients' employer in relation to their chronic illness. It also lends further support to the argument that various sources of social support can influence the health outcomes of chronically ill patients (54).

The present findings emphasise the importance of acknowledging the contribution of the work environment in the experience of psychological distress for chronic illness patients. Managing an illness at work may pose a common challenge for many patients, independent of 
diagnosis. For example, while the behaviour of monitoring symptoms may differ according to illness diagnosis and severity, the nature of the task is the same for those managing a chronic illness at work (27). By using two distinct measures of distress, we were able to identify key psychosocial factors associated with both types of distress experienced in the workplace and an additional but important factor of disclosure at work associated specifically with healthrelated distress. The two types of distress experienced suggest that interventions may affect distress differently. For example, employers providing clear, supportive policies in disclosing an illness may help to reduce health-related distress. Recognising the need for short spells of absence by employees managing a chronic illness may also help reduce health-related distress and subsequent long-term absence. Training line managers to provide appropriate work adjustments and healthcare professionals to target illness self-management skills appropriate to specific workplace settings may be effective in reducing general psychological distress.

There are several limitations to this study. Despite incentives to complete the questionnaire and repeated reminders, the study achieved a low response rate which may represent a potential source of response bias. A number of explanations may account for the low response rates in this study. First, discussions with participating organisations confirmed observations of survey fatigue. This is an increasing problem faced by researchers conducting organisational based research, despite usage of response-inducing techniques (36). Second, although the questionnaire asked for information from those with and without a chronic illness, the main the focus of the questionnaire concerned chronic illness management and it may be that many non-responders felt the questionnaire was irrelevant. Third, the study relied entirely on self-report data in identifying those with chronic illnesses, which may have either resulted in under-reporting of chronic illnesses, leading to a somewhat lower response rate. Those with a chronic illness may have felt distressed or uncomfortable in completing the questionnaire, or felt their illness posed no problem at work or simply chose not to fill it in due to lack of time. Nevertheless, demographic comparisons between responders and nonresponders indicated no serious problems with response bias. This study focused on the 
primary reported condition most affecting work. Many chronic illnesses however, are subject to one or several other associated chronic conditions, such as depression (e.g. 32), which can further complicate the experience of psychological stress. Finally, despite the evidence that a number of psychosocial factors were associated with psychological and health-related distress, as the study was cross-sectional, the causality of the relationships cannot be ascertained. It is could be that the presence of psychological and health-related distress interferes with managing both work and illness. Further longitudinal research is needed to delineate the direction of these relationships.

Understanding different types of distress in those managing a chronic illness is the first step for both employers and healthcare professionals in helping individuals manage their illness within specific environments such as the workplace. Designing and implementing appropriate intervention strategies is likely to promote such employees' physical and psychological wellbeing and prevent concurrent psychological morbidity. The focus of this study is worthy of further attention not only from a research perspective but also from the point of collaboration between healthcare professionals and industries. 


\section{REFERENCES}

[1] Yu DSF, Lee DTF, Woo J, Thompson DR: Correlates of psychological distress in elderly patients with congestive heart failure. J Psychosom Res. 2004; 57: 573-581.

[2] Brisson C, LeBlanc R, Bourbonnais R, et al. Psychologic distress in postmyocardial infarction patients who have returned to work. Psychosom Med. 2005; 67: 59-63.

[3] Ackerman RT, Rosenman MB, Downs SM, Holmes AM, Katz BP, Li J, et al: Telephonic case-finding of major depression in Medicaid chronic disease management program for diabetes and heart failure. Gen Hosp Psychiatry. 2005; 27 : $338-343$.

[4] Heijmans M, Rijken M, Foets M, de Ridder D, Schreurs K, Bensing J: The stress of being chronically ill: from disease-specific to task-specific aspects. J Behav Med. $2004 ; 27: 255-271$.

[5] Curtis R, Groarke A, Coughlan R, Gsel A: Psychological distress as a predictor of psychological adjustment and health status in patients with rheumatoid arthritis. Patient Ed Counsel. 2005; 59: 192-198.

[6] Walker JG, Jackson HJ, Littlejohn GO: Models of adjustment to chronic illness: using the example of rheumatoid arthritis. Clin Psychol Review. 2004; 24: 461-488.

[7] Rief W, Martin A, Klaiberg A, Brähler E: Specific effects of depression, panic and somatic symptoms on illness behaviour. Psychosom Med. 2005, 67: 596-601.

[8] Katon W, Ciechanoswki P: The impact of major depression on chronic medical illness. J Psychosom Res. 2002; 53: 859-863.

[9] Maes S, Leventhal H, Ridder DTD: Coping with chronic diseases. In: Zeidner M, Endler N, eds. Handbook of coping: theory, research and applications. New York: Wiley, 1996. p. 221-251.

[10] Zautra, AJ: Investigations of the ongoing stressful situations among those with chronic illness. Am J Community Psychol. 1996; 24: 697-717.

[11] Ben-sira, Z: Chronic illness, stress and coping. Soc Sci Med. 1984; 18: 725-736. 
[12] Lazarus RS, Folkman S: Stress, appraisal and coping. New York: Springer, 1984.

[13] Livneh H, Lott SM, Antonak RF: Patterns of psychological adaptation to chronic illness and disability: a cluster analytic approach. Psychol, Health Med. 2004; 9: 411-430.

[14] European Foundation for the Improvement of Living and Working Conditions: Employment and disability: back to work strategies. Luxembourg Office for Official Publications of the European Communities, 2004.

[15] Health \& Safety Executive: Self-reported work-related illness 2003/2004. Sudbury, Suffolk: HSE Books, 2004.

[16] Karasek RA: Job demands, job decision latitude, and mental strain.: implications for job redesign. Admin Sci Quart. 1979; 24: 285-308.

[17] De Lange AH, Taris TW, Kompier MAJ, Houtman ILD, Bongers, PM: The relationships between work characteristics and mental health: examining normal, reversed and reciprocal relationships in a 4-wave study. Work Stress. 2004; 18: 149166.

[18] Gilbreath B, Benson PG: The contribution of supervisor behaviour to employee psychological well-being. Work Stress. 2004; 18: 255-266.

[19] Hardy GE, Woods D, Wall TD: The impact of psychological distress on absence from work. J Appl Psychol. 2003; 88: 306-314.

[20] Karasek RA, Theorell T: Health work: stress, productivity, and the reconstruction of working life. New York: Basic Books, 1990.

[21] Akabas SH, Gates LB: Stress and disability management project. Center for Social Policy and Practice in the Workplace, Columbia University: Report for NIDRR, 1993.

[22] Cox T, Thirlaway M, Gotts G, \& Cox S. The nature and assessment of general wellbeing. J Psychosom Res. 1983; 27: 353-359.

[23] Abram HS: The psychology of chronic illness. Journal of Chronic Diseases. 1972, 25: 641-659. 
[24] Randall R, Griffiths A, Cox T. The activation of mechanisms linking judgements of work design and management with musculoskeletal pain. Ergonomics. 2002; 45: 1331.

[25] Warr PB: The measurement of well-being and other aspects of mental health. J Occup Psychol. 1990; 63: 193-210.

[26] Burton WN, Chen C, Conti DJ, Schultz AB, Edington DW. The association between health risk change and presenteeism change. J Occup Environ Med. 2006; 48: 252263.

[27] Munir F, Leka S, Griffiths A: Dealing with self-management of chronic illness at work: predictors for self-disclosure. Soc Sci Med. 2005; 60: 1397-1407.

[28] Aronsson G, Gustafsson K, Dallner M: Sick but yet at work. An empirical study of sickness presenteeism. J Commun Health. 2000; 54: 502-509.

[29] Goetzel RZ, Long, SR, Ozminkowski, RJ, Hawkins K, Wang S, Lynch W: Health, absence, disability, and presenteeism costs estimates of certain physical and mental health conditions affecting U.S. employers. J Occup Environ Med. 2004; 46: 398412.

[30] Munir F, Leka S, Griffiths A: Work limitations and employer adjustments for employees with chronic illness. In J Rehab Res. 2005, 28: 111-117.

[31] Huebner DM, Davis M: Gay and bisexual men who disclose their sexual orientations in the workplace have higher workday levels of salivary cortisol and negative affect. Annals Behav Med. 2005; 30: 260-267.

[32] Lewin R: Return to work after MI, the roles of depression, health beliefs and rehabilitation. Int J Cardio. 1999; 72: 49-51.

[33] Henderson M, Glozier N, Elliot KH: Long term sickness absence - is caused by common conditions and needs managing. Brit Med J. 2005; 330: 802-803.

[34] Baruch Y: Response rate in academic studies - a comparative analysis. Hum Rel. $1999 ; 52: 345-353$. 
[35] Roth PL, BeVier CA: Response rates in HRM?OB survey research: Norms and correlates, 1990-1994. J Manage. 1998; 24: 97-117.

[36] Ibeh K, Brock JK-U, Zhou YJ: The drop and collect survey among industrial populations: theory and empirical evidence. Ind Market Manage. 2004; 33: 155-165.

[37] European Foundation for the Improvement of Living and Working Conditions. Employment and disability: back to work strategies. Luxembourg Office for Official Publications of the European Communities, 2003.

[38] Dewa CS, Lin E: Chronic physical illness, psychiatric disorder and disability in the workplace. Soc Sci Med. 2000; 51: 41-50.

[39] Lerner D, Amick BC, Malspeis S, Rogers WH. A national survey of health-related work limitations among employed persons in the United States. Disabil Rehab. 2000; 22: $225-232$.

[40] World Health Organization. International Classification of Diseases - version $10 .$. Geneva: World Health Organization, 1999.

[41] Pincus Y, Esther R, DeWalt DA, Callaghan LF. Social conditions and selfmanagement are more powerful determinants of health than access to healthcare. Ann Intern Med. 1998; 129: 406-411.

[42] Lorig K Stewart A Ritter P Gonzalez V Laurent D Lynch J. Outcome measures for Health Education and other Health Care Interventions. Sage, Thousand Oaks, 1996.

[43] Clark NM Dodge, JA. Exploring self-efficacy as a predictor of disease management. Health Educ Behav 1999; 26: 72-89.

[44] Lerner DJ, Amick III BC, Rogers WH, Malspeis S, Bungay K. The work limitations questionnaire: A self-administered instrument for assessing on-the-job work disability. Med Care. 2001; 39: 72-85.

[45] Thomson L, Griffiths A, Davison S: Employee absence, age and tenure: a study of nonlinear effects and trivariate models. Work Stress. 2000, 14: 16-34.

[46] Hanebuth D, Meinel M, Fischer JE. Health-related quality of life, psychosocial work conditions, and absenteeism in an industrial sample of blue- and white-collar 
employees: A comparison of potential predictors. J Occup Environ Med. 2006; 48: 28-37.

[47] Johns G: Absenteeism estimates by employers and managers: divergent perspectives and self-serving perceptions. J Appl Psychol. 1994; 79: 229-239.

[48] Kirchmeyer C, Cohen A: Different strategies for managing the work/non-work interface: A test for unique pathways to work outcomes. Work Stress. 1999; 13: 5973.

[49] Johns G: How often were you absent? A review of self-reported absence data. J Appl Psychol. 1994; 79: 574-591.

[50] Stewart AL, Hays RD, Ware JE: Health perceptions, energy/fatigue, and health distress measures. In AL Stewart AL, Ware JE, eds. Measuring Functioning and well-being: the medical outcomes study approach. Durham, NC: Duke University Press, 1992. p.143-72

[51] Gignac AM, Badley EM, LaCaille D, Cott CC, Adam P, Anis AH: Managing arthritis and employment: making arthritis-related work changes as a means of adaptation. Arth Rheum. 2004; 15: 909-916.

[52] Gignac AM: Arthritis and employment: an examination of behavioural coping efforts to manage workplace activity limitations. Arth Rheum. 2005; 3: 328-336.

[53] Burton WN, Pransky G, Conti DJ, Chen C-Y, Edington DW. The association of medical conditions and presenteeism. J Occup Environ Med. 2004; 46: S38-S45.

[54] Caplan G: Support systems and community mental health. New York: Basic Books, 1974. 
Table 1: Demographic details across participants $(n=1029)$

\begin{tabular}{|c|c|c|c|c|c|c|c|}
\hline Chronic Illness & $\begin{array}{c}\text { Musculokseletal } \\
\text { pain } \\
(\mathrm{N}=324)\end{array}$ & $\begin{array}{c}\text { Arthritis \& } \\
\text { rheumatism } \\
(\mathrm{N}=192)\end{array}$ & $\begin{array}{l}\text { Asthma } \\
(\mathrm{N}=174)\end{array}$ & $\begin{array}{c}\text { Depression \& } \\
\text { anxiety } \\
(\mathrm{N}=152)\end{array}$ & $\begin{array}{l}\text { Heart disease } \\
\qquad(\mathrm{N}=96)\end{array}$ & $\begin{array}{l}\text { Diabetes } \\
(\mathrm{N}=91)\end{array}$ & $p$ value $^{1}$ \\
\hline Gender (male) $n(\%)$ & $153^{\mathrm{c}}(47.9)$ & $59^{\mathrm{a}}(30.8) \mathrm{a}$ & $77^{\mathrm{c}}(27.9)$ & $63^{\mathrm{c}}(41.4)$ & $69^{\mathrm{b}}(72.0)$ & $54^{\mathrm{b}}(59.3)$ & $<.0001$ \\
\hline Age & $45.27^{\mathrm{a}}(8.70)$ & $50.22^{\mathrm{b}}(7.88)$ & $43.74^{\mathrm{a}}(7.22)$ & $44.04^{\mathrm{a}}(8.89)$ & $51.37^{\mathrm{b}}(7.22)$ & $48.35^{\mathrm{b}}(7.37)$ & $<.0001$ \\
\hline Tenure & $13.039 .42)$ & $14.50(9.10)$ & $12.18(10.17)$ & $12.69(9.27)$ & $16.80(10.78)$ & $15.59(10.49)$ & ns \\
\hline Socio-economic status & $4.10(1.60)$ & $4.29(1.70)$ & $4.23(1.70)$ & $3.81(1.66)$ & $3.79(1.66)$ & $3.78(1.63)$ & ns \\
\hline Education level & $3.29(1.71)$ & $2.82(1.62)$ & $3.23(1.71)$ & $3.57(1.64)$ & $3.11(1.64)$ & $3.27(1.66)$ & ns \\
\hline No. of chronic illnesses & $1.60(0.80)$ & $1.88(0.98)$ & $1.65(0.99)$ & $1.78(0.98)$ & $1.63(0.99)$ & $1.51(0.83)$ & $\mathrm{ns}$ \\
\hline Illness severity & $3.14^{\mathrm{a}}(1.59)$ & $3.23^{\mathrm{a}}(1.51)$ & $2.52^{\mathrm{b}}(1.43)$ & $3.19^{\mathrm{a}}(1.62)$ & $2.17^{\mathrm{b}}(1.66)$ & $2.14^{\mathrm{b}}(1.28)$ & $<.0001$ \\
\hline
\end{tabular}

Mean (SD) or number of cases (\%) are presented. ${ }^{\mathrm{I}}$-value for chi2 (Gender) or ANOVA (all other variables). Means with different superscripts in a row differ significantly from each other at least at ${ }^{*} p \leq .003$. 
Table 2: Comparison of key variables across participants $(n=1029)$

\begin{tabular}{|c|c|c|c|c|c|c|c|}
\hline Chronic Illness & $\begin{array}{c}\text { Musculokseletal } \\
\text { pain } \\
(\mathrm{N}=324)\end{array}$ & $\begin{array}{c}\text { Arthritis \& } \\
\text { rheumatism } \\
(\mathrm{N}=192)\end{array}$ & $\begin{array}{l}\text { Asthma } \\
(\mathrm{N}=174)\end{array}$ & $\begin{array}{c}\text { Depression \& } \\
\text { anxiety } \\
(\mathrm{N}=152)\end{array}$ & $\begin{array}{c}\text { Heart disease } \\
\qquad(\mathrm{N}=96)\end{array}$ & $\begin{array}{l}\text { Diabetes } \\
(\mathrm{N}=91)\end{array}$ & $p$ value $^{1}$ \\
\hline & Mean (SD) & Mean (SD) & Mean (SD) & Mean (SD) & Mean (SD) & Mean (SD) & \\
\hline General psychological well-being & $26.36^{\mathrm{b}}(7.00)$ & $26.99^{\mathrm{b}}(6.55)$ & $25.96^{\mathrm{b}}(7.07)$ & $34.83^{\mathrm{a}}(6.97)$ & $25.14^{\mathrm{b}}(6.55)$ & $24.74^{\mathrm{b}}(7.07)$ & $<0.0001$ \\
\hline Health-related distress & $2.02^{\mathrm{b}}(1.25)$ & $1.93^{\mathrm{b}}(1.29)$ & $1.48^{\mathrm{c}}(1.25)$ & $2.56^{\mathrm{a}}(1.36)$ & $1.41^{\mathrm{c}}(1.69)$ & $1.61^{\mathrm{c}}(1.30)$ & $<0.0001$ \\
\hline Illness management & $4.79^{\mathrm{a}}(1.54)$ & $5.20^{\mathrm{a}}(1.65)$ & $5.84^{\mathrm{b}}(1.83)$ & $4.20^{\mathrm{a}}(1.53)$ & $5.67^{\mathrm{b}}(1.83)$ & $5.83^{\mathrm{b}}(1.77)$ & $<0.0001$ \\
\hline Disclosure & $1.15^{\mathrm{b}}(0.48)$ & $1.19^{\mathrm{b}}(0.48)$ & $0.96^{\mathrm{a}}(0.46)$ & $1.08(0.49)$ & $1.19^{\mathrm{b}}(0.58)$ & $1.26^{\mathrm{b}}(0.46)$ & $<0.0001$ \\
\hline Work Limitation & $8.73^{\mathrm{b}}(6.70)$ & $8.60^{\mathrm{b}}(6.38)$ & $5.80^{\mathrm{c}}(6.60)$ & $11.77^{\mathrm{a}}(6.14)$ & $6.38^{\mathrm{c}}(6.96)$ & $6.71^{\mathrm{c}}(6.77)$ & $<0.0001$ \\
\hline Workplace Instrumental support & $1.69(0.85)$ & $1.72(0.93)$ & $1.57(0.87)$ & $1.57(0.81)$ & $1.67(0.86)$ & $1.58(0.93)$ & ns \\
\hline Spells of $<5$ days absence & $0.64(0.73)$ & $0.66(0.72)$ & $0.65(0.73)$ & $0.74(0.75)$ & $0.56(0.71)$ & $0.64(0.79)$ & ns \\
\hline Spells of $\geq 5$ days absence & $0.44(0.60)$ & $0.41(0.63)$ & $0.42(0.64)$ & $0.66(0.60)$ & $0.34(0.57)$ & $0.44(0.60)$ & ns \\
\hline Spells of $<5$ days presenteeism & $0.72^{\mathrm{ad}}(0.74)$ & $0.80^{\mathrm{bc}}(0.78)$ & $0.50^{\mathrm{a}}(.0 .66)$ & $0.88^{\mathrm{bc}}(0.91)$ & $0.57^{\mathrm{ad}}(0.69)$ & $0.58^{\mathrm{ad}}(0.77)$ & $<0.0001$ \\
\hline Spells of $\geq 5$ days presenteeism & $0.17(0.45)$ & $0.17(0.48)$ & $0.17(0.48)$ & $0.21(0.56)$ & $0.50(0.24)$ & $0.17(0.49)$ & ns \\
\hline
\end{tabular}


Table 3: Correlations among the key variables

\begin{tabular}{|c|c|c|c|c|c|c|c|c|c|c|c|c|c|c|c|c|c|c|c|}
\hline Variables & $M$ & $S D$ & 1 & 2 & 3 & 4 & 5 & 6 & 7 & 8 & 9 & 10 & 11 & 12 & 13 & 14 & 15 & 16 & 17 \\
\hline 1. Gender ${ }^{\mathrm{a}}$ & - & - & - & & & & & & & & & & & & & & & & \\
\hline 2. Age & 46.62 & 0.30 & -0.02 & - & & & & & & & & & & & & & & & \\
\hline 4. Socio-economic status & 4.04 & 0.05 & $-0.17 * *$ & 0.04 & -0.08 & - & & & & & & & & & & & & & \\
\hline 5. Education level & 3.22 & 0.05 & 0.01 & $-0.18 * *$ & -0.22 & $-0.56^{* *}$ & - & & & & & & & & & & & & \\
\hline 6. No. of chronic illnesses & 1.67 & 0.29 & $0.10^{*}$ & $0.16^{*}$ & 0.04 & $0.14^{*}$ & & - & & & & & & & & & & & \\
\hline 7. Illness severity & 1.65 & 0.24 & -0.07 & 0.04 & 0.06 & 0.09 & $-0.14 *$ & $0.13^{*}$ & - & & & & & & & & & & \\
\hline $\begin{array}{l}\text { 8. General Psychological well- } \\
\text { being }\end{array}$ & 27.51 & 0.24 & $0.15^{* *}$ & -0.05 & 0.04 & 0.03 & $-0.10^{*}$ & $0.22 * *$ & $0.26 * *$ & - & & & & & & & & & \\
\hline 9. Health-related distress & 1.90 & 0.04 & 0.02 & -0.04 & 0.02 & 0.05 & $-0.10^{*}$ & $0.21^{* *}$ & $0.40^{* *}$ & $0.47 * *$ & - & & & & & & & & \\
\hline 10. Illness management & 5.06 & 0.06 & 0.03 & 0.06 & -0.03 & -0.01 & 0.02 & -0.05 & $-0.17^{*}$ & $-0.31 * *$ & $-0.26 * *$ & - & & & & & & & \\
\hline 11. Disclosure & 1.13 & 0.02 & 0.04 & 0.06 & 0.14 & 0.03 & -0.07 & $0.10^{*}$ & $0.17 *$ & 0.03 & $0.20^{*}$ & $-.22 * *$ & - & & & & & & \\
\hline 12. Work limitation & 8.42 & 0.22 & 0.06 & -0.01 & 0.09 & $0.15^{*}$ & $-0.20^{* *}$ & 0.13 & $0.26 * *$ & $0.41 * *$ & $0.39 * *$ & $-0.23 * *$ & 0.12 & - & & & & & \\
\hline 14. Spells of $<5$ days absence & 0.65 & 0.24 & $0.13^{*}$ & $-0.11 *$ & -0.07 & -0.08 & $0.11^{*}$ & 0.07 & -0.03 & 0.08 & 0.01 & 0.04 & 0.02 & -0.09 & 0.07 & - & & & \\
\hline 15. Spells of $\geq 5$ days absence & 0.45 & 0.19 & -0.01 & -0.01 & 0.01 & 0.10 & -0.10 & 0.09 & $0.21 * *$ & $0.20^{* *}$ & $0.28 * *$ & -0.10 & $0.23 * *$ & $0.22 * *$ & 0.07 & $-0.17^{*}$ & - & & \\
\hline $\begin{array}{l}\text { 16. Spells of }<5 \text { days } \\
\text { presenteeism }\end{array}$ & 0.70 & 0.24 & 0.07 & -0.08 & -0.09 & -0.05 & 0.01 & 0.05 & 0.04 & $0.23 * *$ & $0.20^{* *}$ & -0.07 & 0.02 & $0.13^{*}$ & -0.05 & $0.24 * *$ & 0.09 & - & \\
\hline $\begin{array}{l}\text { 17. Spells of } \geq 5 \text { days } \\
\text { presenteeism }\end{array}$ & 0.16 & 0.01 & 0.04 & -0.01 & 0.03 & 0.14 & -0.12 & 0.06 & $0.22 *$ & $0.24 * *$ & $0.21 * *$ & -0.06 & $0.11 *$ & $0.20^{* *}$ & 0.03 & 0.07 & $0.14^{*}$ & $-0.22 * *$ & - \\
\hline
\end{tabular}


Table 4: Hierarchical regression analyses predicting psychological and health-related

distress $(\mathbf{n}=1029)$

\begin{tabular}{|c|c|c|c|c|c|c|c|c|c|c|}
\hline Variables & \multicolumn{5}{|c|}{ Psychological well-being } & \multicolumn{5}{|c|}{ Health distress } \\
\hline & $R^{2}$ & $\Delta R^{2}$ & $B$ & $\mathrm{SE}$ & $\beta$ & $R^{2}$ & $\Delta R^{2}$ & $B$ & SE & $\beta$ \\
\hline $1^{\mathrm{a}}$ & 0.03 & $0.03 * * *$ & & & & 0.01 & $0.01 * *$ & & & \\
\hline Gender & & & 1.52 & 0.38 & $0.10 * *$ & & & - & - & - \\
\hline Educational level & & & -0.07 & 0.16 & -0.02 & & & 0.00 & 0.02 & 0.00 \\
\hline $2^{\mathrm{b}}$ & 0.27 & $0.24 * * *$ & & & & 0.20 & $0.19^{* * *}$ & & & \\
\hline Illness severity & & & 0.85 & 0.27 & $0.08 * *$ & & & 0.42 & 0.05 & $0.24 * * *$ \\
\hline No. of chronic illnesses & & & 1.17 & 0.21 & $0.14 * * *$ & & & 0.15 & 0.04 & $0.10^{* * *}$ \\
\hline Musculoskeletal pain & & & -0.28 & 0.55 & -0.02 & & & -0.08 & 0.10 & 0.03 \\
\hline Arthritis and rheumatism & & & 0.04 & 0.55 & 0.00 & & & -0.06 & 0.10 & -0.02 \\
\hline Asthma & & & 1.18 & 0.58 & $0.06^{*}$ & & & -0.11 & 0.11 & -0.03 \\
\hline Depression \& anxiety & & & 6.21 & 0.59 & $0.30^{* * *}$ & & & 0.24 & 0.11 & $0.06^{*}$ \\
\hline Heart disease & & & 1.56 & 0.72 & $0.06^{*}$ & & & -0.18 & 0.14 & -0.04 \\
\hline Diabetes & & & -0.02 & 0.73 & -0.00 & & & -0.25 & 0.14 & -0.00 \\
\hline $3 \mathrm{c}$ & 0.43 & $0.15^{* * *}$ & & & & 0.35 & $0.15^{* * *}$ & & & \\
\hline Illness management & & & -0.74 & 0.12 & $-0.17 * * *$ & & & -0.10 & 0.02 & $-0.13 * * *$ \\
\hline Disclosure & & & - & - & - & & & 0.47 & 0.08 & $0.18 * * *$ \\
\hline Work Limitation & & & 0.22 & 0.03 & $0.20^{* * *}$ & & & 0.04 & 0.01 & $0.19 * * *$ \\
\hline Workplace Instrumental support & & & -0.47 & 0.22 & $-0.05^{*}$ & & & -0.18 & 0.05 & $-0.12 * * *$ \\
\hline Spells of $\geq 5$ days absence & & & 0.56 & 0.31 & 0.05 & & & 0.21 & 0.06 & $0.10^{* *}$ \\
\hline Spells of $<5$ days presenteeism & & & 1.82 & 0.25 & $0.19^{* * *}$ & & & 0.22 & 0.05 & $0.14 * * *$ \\
\hline Spells of $\geq 5$ days presenteeism & & & 2.71 & 0.43 & $0.17 * * *$ & & & 0.25 & 0.08 & $0.10^{* *}$ \\
\hline
\end{tabular}

${ }^{*} p<.05 * * p<.01 * * * p<.0001$. a Covariates gender and education level; ${ }^{\mathrm{b}}$ covariates illness severity, no. of chronic illnesses and illness groups (coded $1=$ that particular illness, $0=$ other illness); ${ }^{\text {cpedictor }}$ variables. 


\section{APPENDIX}

\section{Example of illness-management item question}

Please answer the following questions on a scale of 1 to 10 , where 1 is 'not very closely at all' and 10 is 'very closely' (Please circle the number that corresponds to you. If not applicable to you, leave blank).

How closely would you say that you are following the Doctor's instructions for taking medication for your health condition

$\begin{array}{llllllllll}\text { Not very closely at all } & 1 & 2 & 3 & 4 & 5 & 6 & 7 & 8 & \end{array}$

\section{Example of illness disclosure item question:}

To what extent have you shared the following information about your health condition with your line manager?

Type of health condition and its symptoms (e.g. pain, fatigue)

Ways in which I manage my condition at work (e.g. taking medication, diet)

The effect of my health condition on my work (e.g. on my ability to perform tasks)

Any time off work needed, related to my health condition

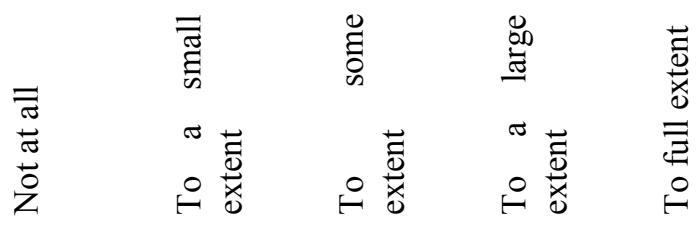

\section{Example of workplace support item question}

With reference to managing your health condition at work, how much practical support (e.g. practical advice and guidance, suitable equipment) is available to you, from the following sources?

Support from....

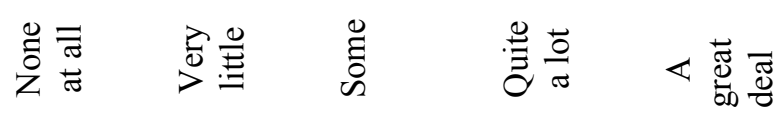

Colleagues

Line Manager or supervisor

Occupational Health 